IZA DP No. 5767

Why Use ROSCAs When You Can Use Banks?

Theory and Evidence from Ethiopia

Abbi M. Kedir

Richard Disney

Indraneel Dasgupta

June 2011 


\title{
Why Use ROSCAs When You Can Use Banks? Theory and Evidence from Ethiopia
}

\author{
Abbi M. Kedir \\ University of Leicester \\ Richard Disney \\ University of Nottingham \\ and IFS \\ Indraneel Dasgupta \\ Centre for Studies in Social Sciences, Calcutta \\ and IZA

\section{Discussion Paper No. 5767 \\ June 2011} \\ IZA \\ P.O. Box 7240 \\ 53072 Bonn \\ Germany \\ Phone: +49-228-3894-0 \\ Fax: +49-228-3894-180 \\ E-mail: iza@iza.org
}

Any opinions expressed here are those of the author(s) and not those of IZA. Research published in this series may include views on policy, but the institute itself takes no institutional policy positions.

The Institute for the Study of Labor (IZA) in Bonn is a local and virtual international research center and a place of communication between science, politics and business. IZA is an independent nonprofit organization supported by Deutsche Post Foundation. The center is associated with the University of Bonn and offers a stimulating research environment through its international network, workshops and conferences, data service, project support, research visits and doctoral program. IZA engages in (i) original and internationally competitive research in all fields of labor economics, (ii) development of policy concepts, and (iii) dissemination of research results and concepts to the interested public.

IZA Discussion Papers often represent preliminary work and are circulated to encourage discussion. Citation of such a paper should account for its provisional character. A revised version may be available directly from the author. 
IZA Discussion Paper No. 5767

June 2011

\section{ABSTRACT}

\section{Why Use ROSCAs When You Can Use Banks? Theory and Evidence from Ethiopia*}

Much of the existing literature on the use of informal credit arrangements such as ROSCAs (Rotating and Credit Saving Associations) theorises the use of such institutions as arising from market failures in the development of formal saving and credit mechanisms. As economic development proceeds, formal institutions might therefore be expected to displace ROSCAs. We show, using household data for Ethiopia, that in fact use of formal institutions and ROSCAs can co-exist, even in the same household. We examine usage of both formal and informal institutions across the household income gradient, and provide a theoretical model consistent with these empirical facts.

JEL Classification: O16, O17

Keywords: household saving, credit institutions, ROSCAs, Ethiopia

Corresponding author:

Richard Disney

School of Economics

University of Nottingham

Nottingham, NG7 2RD

United Kingdom

E-mail: richard.disney@nottingham.ac.uk

\footnotetext{
* We are grateful for useful comments provided by participants of the CSAE Conference, St Catherine's College, University of Oxford, and also by seminar participants at the Universities of Leicester and Nottingham, UK.
} 


\section{Introduction}

Rotating Saving and Credit Associations (ROSCAs) are informal saving and credit institutions that are pervasive in developing countries and among immigrant communities in some developed countries. In ROSCAs, groups of individuals voluntarily pool their regular savings, with disbursements determined either by random draw or bidding until every member has received the 'pot'. The economic literature on ROSCAs, which has expanded apace since the seminal contributions of Besley et al. (1993, 1994), has typically rationalised the existence of ROSCAs as informal responses to diverse financial market failures that are deemed commonplace in developing countries and among immigrant communities in developed economies. ${ }^{1}$ These market failures are assumed to constrain poor people's access to both credit markets and to formal instruments of saving, such as bank accounts. The existence of ROSCAs is thereby explained by identifying different ways in which such institutions mitigate these financial constraints, even if in limited, second best, fashion.

If ROSCAs are rationalised as responses to the failure of formal financial markets, then ROSCAs should tend to be displaced during the process of economic development; indeed their continued existence among some communities in economies with widespread access to formal banking and other credit /saving institutions would be a mystery. The question of who is more likely to participate in, and thereby benefit from, ROSCAs in a world where formal credit and saving institutions also exist is therefore a topic of great interest. In contrast, in a stylized world where ROSCAs are the only instrument available for both saving and borrowing, such as that typically considered in the existing theoretical literature, this question is evidently redundant.

One plausible suggestion might be that, even within a developed economy with formal credit institutions, certain households, such as those with low incomes, might face major credit constraints due to the absence of collateral. Consequently they would not be

\footnotetext{
1 In the models of Besley et al. (1993, 1994), ROSCAs solve the indivisibility problem associated with purchases of lumpy goods in the absence of credit markets, by allowing participants to benefit from pooling their savings. Empirical evidence by Handa and Kirton (1999) confirms this view. Other contributors point to market failures associated with insurance motives to rationalise the existence of ROSCAs, where such institutions allow insurance against adverse wealth shocks (Calomiris and Rajaraman, 1998), or permit individuals to negotiate contracts in the presence of information asymmetries (Klonner, 2003). A further strand of the literature places ROSCAs in their social context, as institutions that allow individuals to fulfil mutual social obligations (Ambec and Treich, 2003; Dagnelie and LeMay, 2005) or serve as a vehicle for saving in households where there are resource allocation conflicts (Anderson and Baland, 2002).
} 
able to access formal credit institutions and would be the residual users of informal institutions such as ROSCAs. As this paper shows however, using evidence from urban Ethiopia where formal and informal credit and saving institutions co-exist, this delineation of users by income status is wide of the mark. Some households appear neither to access informal institutions such as ROSCAs nor formal saving and credit institutions, whilst other individuals and households use both formal and informal saving and credit institutions (banks). While such differential use may be in part related to heterogeneous tastes or preferences, we also show that usage of both sets of institutions is related to the income gradient in a systematic fashion, albeit not in the manner hypothesised at the start of this discussion. This requires an alternative theorisation of how income levels affect ROSCA participation, which is provided in the present paper.

The line of investigation that we wish to explore has an intuitive theoretical entry point. Interest-paying bank savings deposits provide a relatively low-yield, but also relatively safe, instrument of investment for poor people. Random draw ROSCAs, in contrast, are inherently risky investments. The basic source of uncertainty in a random ROSCA is the randomness in the timing of the payout. Since ROSCAs do not pay interest as such, a late payout effectively implies the loss of the interest income that a bank deposit would have generated. However, given borrowing constraints, an early ROSCA payout provides the major source of financing for lumpy but high yield investment in capital goods, including consumer durables. Thus, ROSCA investment is risky but high yield, whereas investment in bank deposits is safe but low yield.

The ensuing problem for a household which cannot borrow is to allocate its savings between these two investment instruments. Seen in this light, the problem becomes one of straightforward investment-portfolio diversification. Analogously, when the purchase of capital assets constitutes an inherently risky investment, formal (bank) credit generates both higher expected returns (because the asset can be purchased for sure) and higher risk (because the loan has to be repaid even in case of investment failure, which becomes more likely with certain purchase) compared to ROSCA financing (which, in effect, involves risk sharing). Thus, access to formal credit need not necessarily preclude ROSCA participation: ROSCA loans may co-exist with, or indeed even displace, formal credit when households are risk averse. There is a parallel here with a limited literature on why credit-constrained individuals may engage in risky strategies such as purchase of lottery tickets as a means of overcoming 
indivisibilities in consumption (Ng, 1965; Crossley et al., 2011), although our theoretical model is somewhat different. ${ }^{2}$

We accordingly set up a simple model of ROSCA participation, where a risk-averse household has to allocate a given amount of savings between a risky but high yield ROSCA and a safe but low yield bank deposit. The ROSCA is risky due to uncertainty over its payout timing, but early payout provides the household with a lump-sum that can be invested in a high yield capital asset, provided this lump-sum is larger than some threshold amount. This investment threshold captures indivisibilities and lumpiness in capital assets. It immediately follows that households with savings large enough to permit direct purchase of the capital good will use neither ROSCAs nor bank deposits as investment outlets, but instead invest directly in the capital good. We identify such households with wealthy households. The investment strategy of poorer households would depend on how risk aversion interacts with the higher expected returns that ROSCAs potentially offer. We show that, given increasing relative risk aversion in wealth, the following pattern is likely to arise. Households are likely to hold only ROSCA accounts at low levels of wealth. However, they will come to save in bank accounts, in addition to ROSCA accounts, once their wealth crosses a certain threshold. Thereafter, bank savings are likely to increase with wealth till the household can afford direct investment in a capital asset. ROSCA savings may also increase with wealth in this intermediate zone if the household's absolute risk aversion diminishes with wealth. Thus, our theoretical analysis shows that, at intermediate levels of wealth, the extent of (i) ROSCA participation, and (ii) simultaneous holding of ROSCA and bank accounts, are both likely to be positively correlated with wealth; while households are likely to use only ROSCA accounts as investment vehicles at low levels of wealth. We also sketch, via a simple example, how our theoretical analysis may be extended to permit access to formal credit: risk aversion may induce households to abjure formal credit in favour of ROSCA credit.

We proceed to offer empirical validation of our theoretical conclusions using data from a panel survey of households in urban Ethiopia (1994-2004). Ethiopian ROSCAs (equb) predominantly involve random draw. Using both parametric and non-parametric techniques, we find that the proportion of respondent households that has ROSCA membership increases with income over an intermediate range. A significant proportion of

\footnotetext{
2 Note also that empirical studies of lotteries generally have data on the behaviour of winners, rather than whether an individual plays the lottery. As shown below, our data are able to show both the propensity to engage in a ROSCA and the level of contribution (saving).
} 
households hold both ROSCA and bank accounts, ${ }^{3}$ and this proportion increases with income over an intermediate range as well. Specifically, the proportion of households saving in ROSCAs shows a quadratic relationship with income: this proportion first rises and subsequently falls. The proportion of households saving in both ROSCAs and bank accounts exhibits a similar relationship with income. Thus, our empirical results support our theoretical conclusions. Moreover, we do not observe that membership of ROSCAs is largely prevalent among wives, as in the Kenyan households discussed by Anderson and Baland (2002), nor that ROSCA membership is particularly prevalent among non-heads of households, or among heads of households that are female rather than male. Our analysis suggests, at a rather more mundane level than quasi-sociological explanations, that formal institutions and ROSCAs provide somewhat different economic functions, and that it is financial considerations that explain the co-existence (i.e. simultaneity of savings both in the formal and informal financial institutions) of these different savings vehicles in the household portfolio. Our theoretical analysis leads us to argue further that lack of access to formal credit per se is not necessary to explain this co-existence: it is rather the absence of formal instruments for sharing of investment risk, such as equity participation and insurance, that provides the conceptual key.

The remainder of the paper is structured as follows. Section 2 provides some relevant institutional details before setting up our model of ROSCA participation. Section 3 outlines our empirical strategy, followed by details of the data used. Section 4 presents our empirical findings. Section 5 concludes. Detailed proofs are presented in the Appendix.

\section{ROSCAs as vehicle for portfolio diversification}

\subsection{Background}

Existing models of ROSCAs do not emphasise that such institutions provide an investment vehicle with a risky but potentially high return, relative to a deposit account at a saving bank paying a known return. Typically throughout the late 1990s and early 2000s, the nominal interest rate on saving deposits in Ethiopian saving institutions was fairly stable at an annual rate of around 6\%, although falling somewhat towards the end of the period. Inflation was more volatile than nominal interest rates, with both year-on-year fluctuations and considerable seasonality, but average returns on deposits were positive, albeit low, over the period. Formal sector borrowing typically incurred a minimum additional premium of $4 \%$

\footnotetext{
${ }^{3}$ Carpenter and Jensen (2002) report a similar finding for Pakistan.
} 
above the deposit rate, reflecting an average nominal rate of return of more than $10 \%$ on direct investment in capital assets. ${ }^{4}$ Thus, ROSCA payouts could yield a significantly higher return than bank deposits, if used to purchase capital assets (including consumer durables) or shares in businesses.

In our urban household survey for Ethiopia, $60-80 \%$ of the respondents did indeed report objectives such as purchasing capital assets and participating in a business venture as their reasons for joining a ROSCA. In the 1994 and 1995 waves of the urban household survey for Ethiopia, around 55-60\% of participants reported their purpose of ROSCA membership to be the purchase of household durables; this proportion was $40 \%$ in the 2000 wave. In addition, around $20 \%$ of the sample consistently reported joining the ROSCA to obtain capital to start or develop a small business. This typically involved using ROSCA payouts to purchase stocks of goods for street vending, or more ambitious projects such as accumulating funds in order to purchase, or make a down payment on, a taxi. Indeed 'taxi equbs' ('equb' being a local term for ROSCAs) are a well-known phenomenon among urban ROSCA participants in Ethiopia. Other uses of funds from equb pay-outs that are documented on the internet include the purchase and resale of second hand cars, and the establishment of small retail outlets such as tea stalls and coffee shops. ${ }^{5}$

Investing in a ROSCA however involves several potential uncertainties. The basic source of uncertainty in a random ROSCA is the timing of the return in the form of the payout. A typical ROSCA in urban Ethiopia has monthly contributions and draws (although weekly ROSCAs are also quite common) and lasts for a cycle of around 2 years, implying that the membership of a ROSCA averages around 24 people. For a typical ROSCA monthly contribution of 30 Ethiopia birr, ${ }^{6}$ the best case scenario therefore for an investor is an initial lump-sum payout of 720 birr, which would yield an income of about 90 birr if invested in a saving deposit for two years, but possibly much more if invested directly in a capital asset for the same period. The worst case scenario is of course one where the investor receives the pay-out in the last round, i.e., at the end of the cycle, thereby achieving a zero nominal return

\footnotetext{
4 See IMF International Financial Statistics, January 2006, Washington DC.

${ }^{5}$ In a similar vein, it is common for communities or groups to raise sufficient capital to purchase an expensive means of transportation as a solution to mobility problems in least developed regions such as Sub-Saharan Africa (World Bank, 1996, p. 26). Note that in the other available wave of the Ethiopian urban survey, 1997, the proportion reporting the durable purchase motive is very much lower, but we ascribe this to a coding error during the transfer of data to an electronic format.

${ }^{6}$ This figure is the average contribution to a ROSCA, taken from the 2000 wave of the Ethiopian urban household survey. 1 US $\$=9.08$ Ethiopian birr. Monthly contributions may average rather more than this since weekly ROSCAs tend to require smaller contributions and we are averaging over ROSCAs with different characteristics.
} 
after two years and a negative real return on the investment. This is the risk that we shall highlight in our formal model of ROSCA participation in Section 2.2 below.

A second source of uncertainty stems from the possibility of a low payout from the ROSCA arising from depletion of members as the early 'winners' opt not to continue their contributions (i.e. defaulting). Social pressures, reflected in the self-selection of ROSCA members from among relatives, friends, or work colleagues should reduce this risk, but this systemic risk may be harder to avoid in the more anonymous urban environment than in a close-knit village setting.

The third source of uncertainty arises from the intended uses of funds drawn from ROSCAs, and whether payouts in practice allow participants to implement their objectives. If the participant has in mind a specific durable purchase, then the risks attached to this investment strategy arise from any subsequent limit on availability of the good in question, along with inflation risk (especially if the good is imported where this risk also incorporates exchange rate risk). With investment-oriented motives, there is the real possibility that the ROSCA disbursement, whenever it occurs, may not be sufficient to realise the planned investment opportunity, quite apart from the possibility that the venture itself may be successful or unsuccessful. If insufficient, participants may buy the cheapest but same durable good (World Bank, 1996). We shall discuss how the introduction of this third form of uncertainty may affect our formal conclusions in Section 2.3 below.

The role of ROSCAs as a risky but high yield investment vehicle has been played down in the literature. It is however at the core of our model of why ROSCAs co-exist with bank savings accounts in urban areas. The lack of basic formal saving institutions in rural areas provides a sufficient rationale for ROSCAs in those settings. In urban areas, however, an increasing proportion of households have access to basic saving and deposit institutions and it is the lack of developed institutions for raising investment capital (arising from the lack of a formal venture capital market, of sophisticated credit scoring agencies etc.) and risk sharing that provides the rationale for the continued existence of ROSCAs. ROSCAs allow households to raise investment capital, and simultaneously to reduce investment risk. However, they do not eliminate investment risk. This residual riskiness in turn provides a rationale for simultaneous saving in bank accounts. On the other hand, credit financed investment provides higher expected returns, but also entails higher risk, than ROSCA financed investment. Consequently, risk averse households may continue to utilize ROSCA credit even when formal investment credit is made available to them. 
In the next section, we develop a formal model in which individuals choose to join ROSCAs with a risky investment motive, while also possibly using bank saving accounts as a safe investment option. To clarify ideas, we develop the model under the assumption that ROSCAs provide the only source of investment capital, i.e., under the assumption of zero credit. In the subsequent section, we indicate how our benchmark analysis may be extended to explain ROSCA holdings even in the presence of investment credit: in the absence of formal risk sharing instruments such as equity participation and insurance, such credit may be deemed too risky, compared to ROSCA financing.

\subsection{A model of ROSCA participation}

Consider a household which has an exogenously given amount of savings (or wealth), $S$, at the beginning of period 1 , which it wishes to invest. It can invest in a bank account at some positive interest rate $r$. Alternatively, it can invest in a capital good which yields a rate of return (flow of capital services) $=(r+d)$ at the end of the period, $d>0 .{ }^{7}$ Thus, the household has a prospective investment opportunity that yields a higher rate of return than bank deposits. However, due to indivisibilities in investment, investment in the capital good will yield this return only if the magnitude of such investment is more than $2 \underline{a}>0 .^{8}$ If investment in the capital good is $2 \underline{a}$ or less no output is generated, so that the initial investment is entirely lost. Household wealth (savings) is more than $\underline{a}$, but may be less than $2 \underline{a}$.

Agents are risk averse: their utility in wealth is given by some diffentiable, strictly concave VNM utility function $u(S)$, where $S$ is the level of savings/wealth.

Due to the assumed absence of collateral, agents cannot borrow. However, they can choose to join a ROSCA at the beginning of period 1. For simplicity, we shall assume that all available ROSCAs are two-person ones. ${ }^{9}$ ROSCAs are differentiated from banks by each having a fixed contribution level and by not paying any interest on accounts. So, if the household joins a ROSCA of level $a$, it pays an amount $a$ at the beginning of the period, and

\footnotetext{
${ }^{7}$ We can allow the rate of return on investment in the capital good to be stochastic, to capture the uncertainties associated with such investment per se. This however adds little to our substantive conclusions.

8 This assumption captures the indivisibility issue noted by Besley et al. (1993, 1994).

9 Generalization to n-person ROSCAs is notationally cumbersome, but does not add any insight. We are assuming that a household can always find a ROSCA of the desired size to join. Essentially, this amounts to assuming that every household can always find an identical household in the population to match and form a ROSCA with: a reasonable assumption in our large population context.
} 
the same amount again at the end. It receives the amount $2 a$ as a ROSCA payment with equal probability at the beginning and the end of the period. ${ }^{10}$ Consequently, by putting its savings in a ROSCA, the household stands to lose the interest payment it could have received from a bank deposit, with probability $\frac{1}{2}$. However, by joining a ROSCA, the household gets to double its investment at the beginning of the period with probability $\frac{1}{2}$. If the ROSCA payout is high enough, it can be used to purchase the investment good and thereby earn a rate of return greater than that provided by bank deposits. In other words, we think of ROSCAs in effect as high yield but risky investments compared to saving through bank deposits.

First note that, if $S>2 \underline{a}$, the household can purchase the investment good outright. In that case, it receives:

$$
E u^{P}=u(S R+S d)
$$

Where $R=1+r$. By joining a ROSCA of level $a>\underline{a}$, its expected utility at the end of the period is:

$$
\begin{aligned}
E u^{R}= & \frac{1}{2}[u(2 a(1+r+d)+(S-a)(1+r)-a)+u((S-a)(1+r)+a)] \\
= & \frac{1}{2}[u(S R+a(r+2 d))+u(S R-a r)],
\end{aligned}
$$

Noting that $a \leq S,(1)$ and (2) together imply that the household's expected return from joining a ROSCA cannot in this case exceed that from investing its entire savings in outright purchase of the capital good. Since households are risk averse, it follows that if $S>2 \underline{a}$, the household will neither join a ROSCA nor invest in a bank account, preferring to invest directly in the capital asset. Thus, when households have high wealth (i.e. $S>2 \underline{a}$ ), they will invest neither in a bank account nor in a ROSCA, but only in the capital good.

Evidently, only that part of the conclusion above which relates to ROSCA holdings is relevant for empirical analysis. At high wealth levels, households are indeed likely to hold bank accounts for two reasons abstracted from in our theoretical analysis. First, these households are much more likely to be engaged in economic activities in the formal sector. Financial transactions, including wage and salary payments, in the formal sector are mostly mediated through banks, and involve cheques and bank drafts. Consequently, transactions

\footnotetext{
${ }^{10}$ We abstract from default risk, i.e. the possibility that an early winner will default on his payments in later rounds, since it is not necessary in order to make our analytical point.
} 
cost considerations would compel high wealth households to hold and operate bank accounts. Second, as discussed earlier, returns from direct investment in capital goods are likely to be inherently risky. Such risk would induce high wealth households to invest some part of their wealth in safe assets, viz. bank deposits. These risks are independent of the risks associated with the timing of ROSCA payouts that we have isolated and highlighted in our formal analysis, but are nevertheless very real. Hence, in reality, high wealth households are likely to hold bank accounts for reasons that are obvious but external to our theoretical analysis; our theoretical analysis however leads us to predict that such households would not hold ROSCA accounts.

Consider now the more interesting case where households have some, but not a large amount of savings, i.e., the case where $S \in(\underline{a}, 2 \underline{a}]$. In this range, the household cannot afford to purchase the investment good outright, but has a 50\% chance of being able to buy it immediately if it joins a ROSCA. Thus, (noting (2)), the expected return from investing only in a ROSCA is $(S R+S d)$, whereas that from investing entirely in a bank account is $S R$. Since in this case the expected income from joining a ROSCA is always higher than that from saving entirely in a bank account, then if households were risk-neutral, they would necessarily invest their entire savings in a ROSCA account. Thus, ROSCA levels chosen by risk-neutral households in this case would be $S$. However, (2) implies that, while ROSCA investment dominates in case of an early payout, bank investment dominates in case of a late payout. Intuitively, it is then clear that risk averse households may choose a mix of ROSCA participation and bank savings. We proceed now to examine this possibility in formal detail.

Denote:

$$
\begin{aligned}
& H \equiv S R+a(r+2 d), \\
& L \equiv S R-a r,
\end{aligned}
$$

and

$$
b \equiv S-a
$$

Then, using (2)-(4), the household's problem can be written as:

$$
\underset{a}{\operatorname{Max}} 2 E u^{R}=[u(H)+u(L)] \text { s.t. } \underline{a} \leq a \leq S .
$$

Using (3)-(6), we get: 


$$
\begin{aligned}
2 \frac{\partial E u^{R}}{\partial a} & =-2 \frac{\partial E u^{R}}{\partial b}=u^{\prime}(H)(r+2 d)-r u^{\prime}(L) \\
& =(r+2 d) u^{\prime}(L)\left[\frac{u^{\prime}(H)}{u^{\prime}(L)}-\left(\frac{r}{r+2 d}\right)\right]
\end{aligned}
$$

Furthermore (noting $u^{\prime \prime}<0$ and using (7)),

$$
2 \frac{\partial E^{2} u^{R}}{\partial a^{2}}=2 \frac{\partial E^{2} u^{R}}{\partial b^{2}}=u^{\prime \prime}(H)(r+2 d)^{2}+r^{2} u^{\prime \prime}(L)<0
$$

By (8), given any $\mathrm{S}$, there must exist a unique solution to the household's maximization problem (6). We shall assume that an interior solution in $a$ exists at $S=2 \underline{a}$.

Assumption 1. $\left.\frac{\partial E u^{R}}{\partial a}\right|_{S=2 \underline{a}, a=\underline{a}}>0>\left.\frac{\partial E u^{R}}{\partial a}\right|_{S=2 \underline{a}=a}$.

In the light of (8), Assumption 1 implies that, at $S=2 \underline{a}$, there exists a unique value of ROSCA holding $a$, say $\vec{a}$, which maximizes expected utility; furthermore, $\vec{a} \in(\underline{a}, 2 \underline{a})$. And in the light of (7), the LHS inequality in Assumption 1 essentially requires that the additional return from investing in the capital asset, $d$, be large enough to justify holding ROSCA investments despite their risky nature. The RHS inequality intuitively requires that the household's risk aversion be strong enough to preclude complete concentration in the risky asset.

We now present our central theoretical finding which shall serve to organize and rationalize our empirical analysis in subsequent sections.

Proposition 1. Let Assumption 1 hold.

(a) Suppose the coefficient of absolute risk aversion is non-decreasing in wealth. Then there exists $\tilde{S} \in(\underline{a}, 2 \underline{a})$ such that:

$$
\text { for all } S \in(\underline{a}, \tilde{S}], a=S \text {; }
$$

and

for all $S \in(\tilde{S}, 2 \underline{a}], a \in(\underline{a}, \tilde{S}]$; with a non-increasing in $S$ in the interval $(\tilde{S}, 2 \underline{a})$. 
(b) Suppose the coefficient of absolute risk aversion is decreasing in wealth, but the coefficient of relative risk aversion is increasing in wealth. Suppose further that $\left.\frac{\partial E u^{R}}{\partial a}\right|_{S=\underline{a}=a}>0$. Then there exists $\tilde{S} \in(\underline{a}, \underline{2} \underline{a})$ such that:

$$
\text { for all } S \in(\underline{a}, \tilde{S}], a=S \text {; }
$$

and

for all $S \in(\tilde{S}, 2 \underline{a}], a \in(\tilde{S}, 2 \underline{a})$; with $a$ and $b$ both increasing in $S$ in the interval $(\tilde{S}, 2 \underline{a})$.

Proof: See the Appendix.

By Proposition 1, at moderate levels of wealth (savings), the household will hold only ROSCA accounts: the higher return in case of an early ROSCA pay-out will more than compensate the household for the forgone interest income (from bank savings deposits) in case of a late ROSCA pay-out. However, at intermediate levels, the household will come to hold a diversified investment portfolio: it will continue to invest in a ROSCA, but open and invest in a bank savings account as well. As wealth increases, so does its loss from investing only in a ROSCA, in terms of forgone interest income in case of a late pay-out. Beyond a point, this loss comes to outweigh the gain in case of an early pay-out, inducing the household to shift part of its wealth from a ROSCA to the safe asset, viz. bank savings deposit. In the intermediate wealth zone, the household will utilize both investment instruments: it may, but need not, reduce its ROSCA exposure in favour of bank deposits as its wealth rises. As already discussed, at high levels of wealth $(S>2 \underline{a})$, the household will not hold ROSCAs; it will instead invest its wealth in the direct purchase of the high yield asset since it can now afford to purchase the capital good outright. It is nevertheless likely to continue holding bank accounts for reasons empirically important but abstracted from in our theoretical enquiry, as discussed earlier.

Note that, if the coefficient of absolute risk aversion $\left(R_{A} \equiv-\frac{u^{\prime \prime}}{u^{\prime}}\right)$ is non-decreasing in wealth, the coefficient of relative risk aversion ( $R_{R} \equiv R_{A} S$ ) must necessarily be increasing in wealth. However, increasing relative risk aversion does not imply non-decreasing absolute 
risk aversion. ${ }^{11}$ Thus, increasing relative risk aversion is a weaker assumption than nondecreasing absolute risk aversion. Essentially, increasing relative risk aversion turns out to be sufficient, without being necessary, to ensure that bank savings turn positive and increase with wealth beyond some threshold wealth level. Whether ROSCA investments will increase as well depends on absolute risk aversion, as specified in Proposition 1. It is intuitively obvious, and easy to formally check, that the threshold level of wealth above which households hold bank accounts ( $\tilde{S}$ in Proposition 1 above) will fall if the bank interest rate increases.

To summarize, Proposition 1 suggests the following testable empirical patterns.

(i) At low levels of wealth, households are likely to hold only ROSCA accounts, and no bank accounts.

(ii) At intermediate levels of wealth, households are likely to hold both ROSCA and bank savings accounts. Bank saving is likely to increase with wealth; ROSCA investment may (though not necessarily) do so as well.

(iii) At high levels of wealth, households are unlikely to hold ROSCA accounts.

\subsection{Extension: ROSCA participation and formal credit}

In line with most of the theoretical literature on ROSCAs, we have assumed in our benchmark model in Section 2.2 that households lack access to credit. This assumption serves to keep the algebra simple, and, arguably, provides a reasonable approximation for the empirical reality facing most poor people in developing countries. It needs to be emphasized, however, that credit constraints are in no way fundamental to our explanation for ROSCA participation. Indeed, risk aversion and portfolio diversification considerations might lead to ROSCA participation even if formal investment credit were available, and households may abjure formal credit in favour of ROSCA financing, or use both forms of investment financing, because of the lower risk associated with ROSCAs, compared to direct borrowing. Rigorous support for, and expansion of, these claims can be provided by following a line of reasoning very similar to the one that leads us to Proposition 1 above. Since that analytical exercise merely involves, in essence, an algebraically more cumbersome retelling of the key

11 To see this, consider the utility function $u=\ln (1+S)$. Then $R_{A}=\frac{1}{(1+S)}$, while $R_{R}=\frac{S}{(1+S)}$. Clearly, $R_{R}$ is increasing in $S$, but $R_{A}$ is decreasing in $S$. 
themes in Section 2.2 above, we do not attempt it here. Such an exercise is of limited interest also because its conclusions do not lend themselves to empirical validation: our data set does not allow us to explicitly test comparative static hypotheses regarding formal credit. We therefore confine ourselves to providing a simple example that highlights the intuition underlying our claims regarding ROSCA participation and formal credit.

Suppose that the expected rate of gross return on investment $I>2 \underline{a}$ in the capital asset is $(R+d)$, as in our benchmark model earlier, but this return is stochastic: it can either be $2(R+d)$ or 0 with equal probability (recall the discussion of investment risk in Section 2.1). As earlier, assume the investment yields 0 output if $I \leq 2 \underline{a}$. Given savings $S \in(\underline{a}, 2 \underline{a}]$, first suppose the household borrows an identical amount and invests the total, $2 S$, in purchase of the capital asset. For simplicity, assume loans are interest free. Then the household receives either $4 S(r+d)+3 S$ or $-S$ with equal probability, net of (interest-free) loan repayment, so that its expected income (net of loan repayment) is $S(R+d)+S(r+d)$. If, instead, the household invests its savings in a ROSCA, it receives $4 S(r+d)+3 S$ or $-S$ with probability $\frac{1}{4}$ each (early payout and subsequent investment), and $S$ with probability $\frac{1}{2}$ (late payout). Hence, the expected income in case of ROSCA investment is $S(R+d)$, as in our benchmark model. Since the expected return from investing via ROSCA is lower than that from investing via direct borrowing, a risk-neutral household would obviously prefer direct borrowing. Notice that, in the absence of investment risk per se, as in our benchmark model of Section 2.2 which assumes a deterministic return on purchase of the capital good, even a risk averse household would evidently prefer direct borrowing to ROSCA financing. However, given stochastic returns on purchase of the capital good, since ROSCA participation reduces the probability of the worst outcome $(-S)$ from $\frac{1}{2}$ to $\frac{1}{4}$, the household would prefer ROSCA participation to direct borrowing if it is sufficiently risk averse. Thus, the implicit risk-sharing offered by ROSCAs may lead to participation by households in such schemes even if they have access to formal credit. The type of portfolio diversification considerations that generate simultaneous holding of bank savings and ROSCA accounts also suggest the possibility that households may borrow from banks as well as ROSCAs.

To sum up, there appears to be no a priori reason to expect that greater access to formal credit per se will necessarily reduce ROSCA participation: it is the absence of formal 
instruments of risk sharing (such as equity participation by lenders or insurance contracts that directly reduce investment risk) which may be conceptually more important in explaining the persistence of ROSCA participation among poor people in developing countries.

\section{Econometric framework and data}

\subsection{Econometric models}

We now proceed to identify econometrically the factors which significantly impact on ROSCA participation, saving in banks and participation in both. We use both non-parametric and parametric econometric specifications to test our propositions.

We wish to specify the shape of the relationship between household saving decisions and wealth. The locally weighted regression is an appropriate method because it does not impose any assumption about functional forms and allows the data itself to choose the parameter estimates and the shape of the curve. In preference therefore to other nonparametric techniques such as the Kernel regression we use the locally weighted regression (Lowess) technique proposed by Cleveland (1979) which is further developed in Cleveland et al (1988). This technique gives a desirable smoother which tends to follow the data. The method "can be thought of as a series of linear regressions at different points appropriately stitched together...”(Deaton, 1997, p.193). The smoothed values are obtained by running a regression of the $\mathrm{y}$ variable (i.e. saving in ROSCAs, banks and both schemes) on the $\mathrm{x}$ variables (i.e. log of total household expenditure or its quadratic variant) with weights which are higher for the central point of the $(\mathrm{y}, \mathrm{x})$ combination than points farther away. According to Cleveland (1979) for each y, its smoothed version, say $y_{i}^{s}$, is computed.

Let $y_{i}$ and $x_{i}$ be the two variables and suppose they are ordered so that $x_{i} \leq x_{i}+1$ for $i=1, \ldots, N-1$. The subset used in calculating $y_{i}^{s}$ is indices $i_{-}=\max (1, i-k)$ through $i_{+}=\min (i+k, N)$, where $k=[N . b a n d w i d t h-0.5 / 2]$. The weights for each of the observations between $j=i_{-}, \ldots, i_{+}$) are either 1 (i.e. no weight) or the tricube (default) ${ }^{12}$,

$$
w_{j}=\left\{1-\left(\frac{\left|x_{j}-x_{i}\right|}{\Delta}\right)^{3}\right\}^{3}
$$

${ }^{12}$ Note that the default bandwidth is 0.8 and Lowess was implemented in STATA using an ado file. 
where $\Delta=1.0001 \max \left(x_{i_{+}}-x_{i}, x_{i}-x_{i_{-}}\right)$. The smoothed value of $y_{i}^{s}$ (saving in any of the schemes) is then the weighted mean regression prediction at $x_{i}$ (log of household expenditure).

Due to the panel nature of the data on savings, we also estimated parametric models such as the random effects (RE) probit. For a reliable interpretation of our final coefficient estimates, we checked the stability of the quadrature approximation. As implied by the stability test, we adopted higher interpolation points to generate our estimated regression coefficients. Consider the model (Arulampalam, 1998):

$$
\begin{aligned}
& y_{i t}^{*}=x_{i t}^{\prime} \beta+v_{i t}, i=1,2, \ldots, n ; t=1,2, \ldots, T ; \\
& v_{i t}=\alpha_{i}+u_{i t} ;
\end{aligned}
$$

and

$$
y_{i t}=1 \text { if } y_{i t}^{*}>0 \text {; and } 0 \text { otherwise; }
$$

where (dropping the subscripts) $y^{*}$ denotes the unobservable variable, $y$ is the observed outcome (i.e., here, saving in ROSCA only, bank only or both) ${ }^{13}, x$ is a vector of timevarying and time invariant regressors that influence $y^{*}, \beta$ is the vector of coefficients associated with the regressors, $\alpha_{i}$ denotes the individual specific unobservable effect and $u_{i t}$ is a random error. We assume that $u_{i t} \sim \operatorname{IN}\left(0, \sigma_{u}^{2}\right)$. In order to marginalize the likelihood, we also assume that, conditional on the $x_{i t}, \alpha_{i}$ s are $\operatorname{IN}\left(0, \sigma_{\alpha}^{2}\right)$ and are independent of $u_{i t}$ and $x_{i t}$. The above assumptions suggest that the correlation between two successive error terms for the same individual is a constant given by; $\rho=\operatorname{cor}\left(v_{i t}, v_{i t-1}\right)=\frac{\sigma_{\alpha}^{2}}{\sigma_{\alpha}^{2}+\sigma_{u}^{2}}$. The parameters of the random effect probit model can be estimated by noting that the distribution of $y_{i t}^{*}$ conditional on $\alpha_{i}$ are independent normal (Heckman, 1981).

To allow for the joint determination of saving in both schemes and potential non-zero covariance of the errors in the ROSCA and bank equations, we further adopted a pooled bivariate probit model ${ }^{14}$. The results of this model serve as a robustness check to our findings under the RE probit model with regard to the relationship between household savings and wealth in Ethiopia. In order to assess more formally the interaction of the formal and the informal saving institutions or financial sectors, we modeled the determinants of

\footnotetext{
${ }^{13}$ When we say saving in ROSCA (bank) only we meant all households which have ROSCA (bank) but no bank (ROSCA) savings.

14 Separate bivariate probit estimates for each of the survey years are available upon request.
} 
saving in the two sectors jointly. The econometric approach adopted was the bivariate probit model, which has the following specification:

$$
\begin{aligned}
& y_{1 i}^{*}=\beta_{1} x_{1 i}+\varepsilon_{1 i}, y_{1 i}=1 \text { if } y_{1 i}^{*} \geq 0,0 \text { otherwise; } \\
& y_{2 i}^{*}=x_{2 i} \beta_{2}+\varepsilon_{2 i}, y_{2 i}=1 \text { if } y_{2 i}^{*} \geq 0,0 \text { otherwise; }
\end{aligned}
$$

where $\left(\varepsilon_{1 i}, \varepsilon_{2 i}\right) \sim \operatorname{BVN}(0,0,1,1, \rho),-1<\rho<1$. Here $y_{1 i}^{*}$ is the propensity of an individual to save in a bank; $y_{1 i}$ is observed formal-sector status; $y_{2 i}^{*}$ is propensity of an individual to save through an equb (ROSCA) and $y_{2 i}$ indicates observed equb status. The two equations (one for the equb and one for the banks) can each be estimated consistently by individual single equation standard probit methods. However, this is inefficient in that it ignores the correlation between the disturbances. This correlation is of interest here because it enables us to assess the strength of the association between the unobservables affecting the propensity of using the two saving schemes. There is no issue of identifiability or estimability if the two equations have identical variables as in our case. ${ }^{15}$

\subsection{Data}

The data in this study were collected in five waves: 1994, 1995, 1997, 2000 and 2004, from seven urban centres in Ethiopia by the Department of Economics of Addis Ababa University in collaboration with the Department of Economics of University of Gothenburg. Due to extreme outliers and unreasonable records which we could not verify by consulting the paper version of the completed questionnaire, we excluded the 1997 sample from our analysis. The cities covered in the survey include Addis Ababa (i.e. the capital city), Awassa, Bahar Dar, Dessie, Diredawa, Jimma and Mekele. A total of 1500 households were interviewed to provide information on household demographics, income, expenditure, education, assets, health and on individual and household participation in formal and informal financial institutions. Across the four waves, the total number of individual members that are declared to be members of ROSCAs ranges from 1600 to 2100. The informant was the economic head of the household (in terms of income source) and was normally (but not always) male. The data were collected at slightly different times of the year in each wave. This is important because household patterns of consumption, and indeed motives for saving,

\footnotetext{
15 We estimate our model using STATA 11.0 with robust/sandwich estimator of variance to estimate the variance-covariance matrix of the estimators.
} 
may differ from month to month. For example, weddings are traditionally held at certain times of the year, and the rainy and dry seasons affect both income and expenditure patterns.

The information on equbs (Ethiopian ROSCAs) asks whether any member of the household is a member of equb, the frequency of saving per month, amount of equb contribution per month, amount paid out by equb and amount expected to be received from equb. We linked the identification (id) code of equb members with the id code from the demographic file to define individual characteristics of equb participants such as gender, age, level of schooling, labour market status, ethnic origin and religious affiliation. Due to the rich array of information at our disposal we also defined equb specific characteristics such as size of equb contribution and size of equb. We are also know from the data whether individuals have a bank account, but we do not know how much, if any, regular saving they are making into this account. From other sections of the data we can also define householdspecific characteristics such as total household expenditure, food expenditure, household size, demographic composition and location.

\section{Econometric Results}

\subsection{Wealth and saving}

We examined the relationship between household wealth and the propensity to save in ROSCAs, banks and both in ROSCAs and banks, using the Lowess regression function described in Section 3. The proportion of households saving in ROSCAS and those saving using both instruments show a non-linear quadratic relationship with the log of household expenditure, as conjectured by our theoretical model (Figures 1 and 3 below). ${ }^{16}$

\section{Insert Figures 1, 2 and 3 around here}

The non-monotone relationship between ROSCA savings and household wealth supports the prediction of Proposition 1, which suggests lower ROSCA participation at both low and high levels of wealth (see Figure 1). Very poor households do not participate in ROSCAs, nor do they hold bank accounts. This is because they have no investible surplus left after meeting their basic subsistence needs. As wealth crosses the subsistence threshold, savings turn positive. For a range of wealth thereafter, some households invest, but only in ROSCAs; the proportion of households who do so increasing in wealth, since at a higher

\footnotetext{
16 We utilise household expenditure rather than income or wealth because we believe that expenditure is better measured than either of the other two indicators, and is more closely correlated with lifetime income and wealth than income and wealth measured in a single period. However results using income and wealth measures are very similar to those illustrated here and are available from the authors on request.
} 
wealth level a larger proportion of households have investible savings. Beyond a savings threshold, some households diversify into bank savings, while continuing to hold ROSCA accounts.

Notice that the threshold beyond which households start holding both bank and ROSCA accounts is higher than that beyond which households start holding ROSCA accounts (Figures 1 and 3), as predicted by Proposition 1. The proportion of such households is higher at higher wealth levels, since a larger proportion of households is above this savings threshold at a higher wealth level. At even higher wealth levels, however, some households withdraw from ROSCA participation, since they can directly purchase investment goods. This leads to a fall in ROSCA participation at very high wealth levels. Even at such wealth levels, however, some households continue to hold ROSCA accounts. These households possibly join largely for non-monetary reasons such as social pressure and self-control problems (Ambec and Treich; 2007, 2003). Thus, the quadratic relationship noted in Figures 1 and 3 can be easily rationalized in terms of our analytical conclusions presented in Proposition 1.

The relationship between bank saving and household wealth is non-linear but not quadratic (see Figure 2). Households in the lower portion of the wealth distribution are less likely to save in banks. At intermediate wealth levels, the proportion of households with bank accounts rises with wealth, as predicted by Proposition 1. As discussed in Section 2.2 above, the importance of bank-mediated formal sector financial transactions for high wealth households, and portfolio diversification considerations in the face of direct investment risks, factors abstracted from in our formal analysis, both serve to explain why the possession of bank accounts keeps rising even at high wealth levels.

In Figure 4 we investigate the relationship between the value of saving in a ROSCA and the log level of household expenditure. It will be noted that saving through ROSCAs increases with income and then peaks, as suggested in Proposition 1(b) above. As noted previously, we do not have data on savings through bank accounts to supplement the data on the propensity to hold a bank account, so we cannot confirm that the second part of Proposition (ii) holds for the level of savings as well as the propensity to save through bank accounts.

Insert Figure 4 near here 
The parametric results based on random effects (RE) and seemingly unrelated pooled bivariate models are summarised below in Tables 1 and 2 respectively. The RE probit estimates show the significant bell-shaped quadratic relationship between households' saving and their wealth position. This is true for ROSCA savings, bank savings as well as simultaneous savings in ROSCAs and banks. This relationship is robust if we interact the quadratic of log of household expenditure with time dummies. ${ }^{17}$

Table 1: Predicting the propensity to save in ROSCAs, banks and simultaneously in ROSCAs and banks.

\begin{tabular}{|c|c|c|c|}
\hline \multirow[t]{2}{*}{ Variables } & \multicolumn{3}{|c|}{ Random Effects (RE) Probit Estimates } \\
\hline & Equb Savings & Bank Savings & Saving in Both \\
\hline Log of expenditure & $1.367 * * *(0.454)$ & $2.995 * * *(0.817)$ & $4.381 * * *(1.174)$ \\
\hline $\begin{array}{l}\text { Log of expenditure } \\
\text { squared }\end{array}$ & $-0.084 * *(0.036)$ & $-0.165 * * *(0.062)$ & $-0.281 * * *(0.087)$ \\
\hline Log of household size & $-0.031 \quad(0.096)$ & $-0.288 * *(0.130)$ & $-0.178 \quad(0.175)$ \\
\hline Years of schooling & $0.006 \quad(0.009)$ & $0.082 * * *(0.013)$ & $0.016 \quad(0.017)$ \\
\hline Age of household head & $-0.015^{* * *}(0.003)$ & $0.006 \quad(0.005)$ & $-0.002 \quad(0.007)$ \\
\hline Gender (1=female) & $0.087 \quad(0.116)$ & $-0.073(0.169)$ & $-0.162 \quad(0.228)$ \\
\hline Married & $0.011 \quad(0.104)$ & $-0.097(0.153)$ & $-0.272 \quad(0.203)$ \\
\hline Employer & $-0.059 \quad(0.309)$ & $1.197 * * *(0.382)$ & $-0.021 \quad(0.508)$ \\
\hline Self employed & $0.383 * * *(0.130)$ & $0.702^{* * *}(1.93)$ & $0.361 \quad(0.236)$ \\
\hline Civil servant & $-0.178 *(0.110)$ & $0.084 \quad(0.148)$ & $0.017 \quad(0.195)$ \\
\hline Skilled worker & $0.922 * * *(0.353)$ & $0.918 * *(0.430)$ & $1.475 * * *(0.520)$ \\
\hline Pensioner & $0.024(0.128)$ & $0.207 \quad(0.172)$ & $0.244 \quad(0.229)$ \\
\hline No of men working & $0.167 * * *(0.049)$ & $0.154 * *(0.074)$ & $0.097 \quad(0.091)$ \\
\hline No of women working & $0.230 * * *(0.043)$ & $0.089 \quad(0.059)$ & $0.158 * *(0.074)$ \\
\hline $\begin{array}{l}\text { No of male children } \\
\text { working }\end{array}$ & $-0.037(0.493)$ & $0.757 \quad(0.712)$ & $0.630 \quad(0.929)$ \\
\hline $\begin{array}{l}\text { No of female children } \\
\text { working }\end{array}$ & $-0.805^{* *}(0.375)$ & $-0.847 *(0.504)$ & $-0.497 \quad(0.703)$ \\
\hline Wald $\chi^{2}$ (p-value) & $178.6^{* * *}(0.000)$ & $216.8^{* * *}(0.000)$ & $99.4^{* * *}(0.000)$ \\
\hline $\begin{array}{l}\text { LR test of } \rho=0 \\
\left(\chi^{2}, p \text {-value }\right)\end{array}$ & $301.1^{* * *}(0.000)$ & $246.2 * * *(0.000)$ & $120.8 * * *(0.000)$ \\
\hline Number of observations & 4243 & 3243 & 4243 \\
\hline
\end{tabular}

\footnotetext{
${ }^{17}$ The interaction terms with all the time dummies were insignificant in all specifications of the random effects and pooled bivariate models.
} 
N.B. Other controls included in the model are location, time and ethnicity dummies. As suggested by quadchk (i.e. quadrature check), we used 20 points instead of 12 in the Gauss_Hermite quadrature.

One of our main interests is to test whether simultaneous bank and ROSCA savings exist in the intermediate level of household wealth. This is corroborated both in the RE and pooled bivariate estimated results. The latter allows for the non-zero covariance of the errors in the ROSCA and bank saving equations. The correlation of the error terms $(\rho)$ is significant which suggests the presence of significant interaction between households' decision of saving in ROSCAs and saving in banks.

Table 2: Seemingly Unrelated Bivariate Probit Estimates of saving propensities (Pooled)

\begin{tabular}{|c|c|c|}
\hline Variables & Equb Savings & Bank Savings \\
\hline Log of expenditure & $0.864 * *(0.340)$ & $1.254^{* * *}(0.452)$ \\
\hline Log of expenditure squared & $-0.056 * *(0.027)$ & $-0.053 *(0.034)$ \\
\hline Log of household size & $0.016(0.063)$ & $-0.220 * * *(0.067)$ \\
\hline Years of schooling & $0.006(0.007)$ & $0.049 * * *(0.007)$ \\
\hline Age of household head & $-0.006 * * *(0.002)$ & $0.002(0.003)$ \\
\hline Gender (1=female) & $-0.001(0.084)$ & $0.022(0.089)$ \\
\hline Married & $-0.064(0.077)$ & $-0.045(0.0821)$ \\
\hline Employer & $0.022(0.221)$ & $0.613 * * *(0.213)$ \\
\hline Self employed & $0.220 * *(0.093)$ & $0.283 * * *(0.098)$ \\
\hline Civil servant & $0.049(0.072)$ & $0.006(0.077)$ \\
\hline Skilled worker & $0.638 * *(0.259)$ & $0.617 * *(0.257)$ \\
\hline Pensioner & $0.069(0.088)$ & $0.110(0.092)$ \\
\hline No of men working & $0.094 * *(0.037)$ & $0.123 * * *(0.039)$ \\
\hline No of women working & $0.180 * * *(0.032)$ & $0.073 * *(0.034)$ \\
\hline No of male children working & $-0.077(0.421)$ & $0.333(0.416)$ \\
\hline No of female children working & $-0.645 * *(0.322)$ & $-0.449(0.297)$ \\
\hline Wald $\chi^{2}$ (p-value) & \multicolumn{2}{|c|}{$616.9 * * *(0.000)$} \\
\hline $\begin{array}{c}\text { LR test of } \rho=0 \\
\left(\chi^{2}, p \text {-value }\right)\end{array}$ & \multicolumn{2}{|c|}{$25.4^{* * *}(0.000)$} \\
\hline Number of observations & 3243 & 3243 \\
\hline
\end{tabular}

N.B. Other controls included in the model are location, time and ethnicity dummies. 


\subsection{Other controls and saving}

Apart from wealth, other socio-economic indicators were also found to be significant in affecting the saving portfolio of households. Since there are no sign reversals and loss of statistical significance in almost all the additional explanatory variables included between the $\mathrm{RE}$ and bivariate probit estimates, all our interpretations below apply to results obtained from both of these modelling frameworks.

Consistent with our prior expectations, education has a significant and positive impact on the propensity to save in banks. This is probably due to: (a) literacy facilitating the operation of bank accounts, and (ii) education being associated with employment in the formal sector where payment is often by cheque, bank drafts, or directly into bank accounts. Larger households are less likely to save in banks and this result can be explained by referring to existing evidence on the relationship between household size and wealth position. Lipton and Ravallion (1994) find a significant negative association between household size and income per person in poor countries such as Ethiopia. Large and poor households often devote their budget almost entirely to subsistence goods and are more likely to have low savings: consequently they are more likely to use only ROSCAs.

Households with older heads are less likely to save in ROSCAs. Households with heads who are skilled workers or self-employed exhibit a higher likelihood of saving both in ROSCAs and banks. Heads who are skilled workers are also more likely to save simultaneously in banks and ROSCAs. Such heads are more likely to be better paid, and to be paid in cheques or directly into bank accounts, rather than in cash. If the head is an ownaccount worker or employer, only bank saving is positively and significantly affected. The number of men and women working significantly increases the likelihood of saving in ROSCAs and banks as shown in Table 2. It is interesting to note that the number of women working in the household increases the likelihood of saving in ROSCAs but not in banks in the RE probit results of Table 1. This is not unexpected because most ROSCAs are formed among women. While the number of working women has a stronger impact on ROSCA saving, the number of men working has a stronger impact on bank saving. In a society such as Ethiopia, men are more likely to be more educated than women. Hence, men are more likely to gain regular employment, which often pays wages directly via bank accounts. This would reinforce their propensity to use banks as a saving vehicle. 
For simultaneous saving both in ROSCAs and banks, the only positive and significant coefficient was that associated with the number of men working. Except for a significantly negative coefficient in the bank saving equation in the bivariate model, ethnicity of the household head does not have a significant role in bank savings. It is however important in ROSCA savings. Amhara, Oromo and Gurage heads are more likely to save in ROSCAs relative to Tigre heads. The ethnic group Gurage constitutes a community famous for its informal commercial activities which often forms into informal mutual support and saving schemes such as ROSCAs. This is not reflected in the ROSCA savings equations. Compared to the capital city (the omitted category), households in Awasa and Bahar Dar are more likely to save in ROSCAs, banks as well as both outlets while households in Diredawa are less likely to use any of the saving options.

\section{Conclusion}

This paper offers a formal analysis of how ROSCA participation and bank saving schemes may simultaneously interact with one another. We show that this depends on a household's wealth position and attitude towards risk. We also provide empirical support for our theoretical deductions. Our empirical estimates use an urban household panel data collected in five waves from seven major urban centres in Ethiopia from 1994 to 2004. Our empirical results support the theoretical proposition which predicts the co-existence of savings both in banks and ROSCAs for intermediate wealth levels. ROSCA participation and the holding of bank accounts both appear to rise with wealth at intermediate levels, in line with our theoretical analysis. Formally examining the interaction of bank and ROSCA savings jointly, we find the errors of the two equations to be statistically significant and positively correlated, which suggests the propensity to save in ROSCAs is not independent of saving in banks. The strong significance of the correlation might also suggest a possible substitution at work between the saving schemes. Our results are robust to alternative specification and using different sub-sample of the observations.

Our analysis provides both theoretical and empirical grounds for suggesting that the moderately poor may invest significantly more in both ROSCA-type schemes and bank savings accounts than the extremely poor. This result has an important bearing on organizing pro-poor micro-credit policies in developing countries. If random draw ROSCA-type mechanisms were intrinsically more likely to attract the poorest sections of the population, then an a priori case might be constructed for both NGOs and governmental organizations to encourage the formation and proliferation of ROSCA-type institutions as a means of 
improving credit access for these sections. Indeed, governments and NGOs in many countries actively encourage savings pooling via formation of 'self-help groups' among the poor (especially women), through matching transfers and/or organizational support: a random draw ROSCA type of disbursal mechanism may then be advanced as the appropriate way in which individual group members are to be permitted to withdraw resources from the group's collective savings pool.

On the other hand, if as suggested here there are strong a priori reasons why the poorest individuals may self-select out from, or, more generally, save less in, random draw ROSCAs, then governments and NGOs would need to adopt other methods of disbursal if they are to effectively address the financing needs of the poorest sections. In addition, if it turns out that individuals who are more likely to save in ROSCAs are less likely to hold bank savings accounts, then a policy of higher interest on small scale bank savings will have only a small effect on the welfare of such individuals. Conversely, if ROSCA savings and bank savings move in tandem, then a rise in the bank savings rate will also benefit ROSCA savers. Such considerations are obviously important in understanding the distributive incidence of changes in the interest rate on bank savings among different sections of the poor.

Lastly, our theoretical analysis leads us to conclude that it is not the absence of formal credit per se, but rather that of formal instruments for risk sharing such as equity participation and insurance, which may provide the conceptual key to understanding the persistence of ROSCA-type mechanisms. It follows that policy interventions which expand the provision of institutional (say, bank) credit to poor households may be more effective in reducing poverty when associated with measures to improve access to such formal risk sharing instruments. Implemented in isolation, the former type of interventions may disproportionately benefit the relatively better off: poorer households may choose to continue their dependence on ROSCAtype informal mechanisms for meeting their financing needs, despite greater availability of formal finance. While the policy literature typically concerns itself with factors constraining the supply of formal credit to poor households, our analysis thus serves to highlight factors possibly constraining its demand.

\section{References}

Ambec, S. and Treich, N. (2007) 'ROSCAs as financial agreements to cope with self-control problems', Journal of Development Economics 82: 120-137.

(2003) 'ROSCAs as financial agreements to cope with, social pressure', mimeo. INRA-GAEL, University of Grenoble, France. 
Anderson, S. and Baland, J-M. (2002) 'The economics of ROSCAs and intrahousehold resource allocation', Quarterly Journal of Economics 117: 963-995.

Arulampalam, W. (1998) 'A Note on estimated coefficients in random effects probit models', mimeo, Department of Economics, University of Warwick, UK.

Besley, T., Coate, S. and Loury, G. (1993) 'The economics of rotating savings and credit associations', American Economic Review 83: 792-810.

Besley, T., Coate, S. and Loury, G. (1994) 'Rotating saving and credit associations: credit markets and efficiency’, Review of Economic Studies 61: 701-719.

Calormiris, C. and Rajaraman, I. (1998) 'The role of ROSCAs: lumpy durables or event insurance?’ Journal of Development Economics 56: 207-216.

Carpenter, S. and Jensen, R. (2002) 'Household participation in formal and informal savings mechanisms: evidence from Pakistan', Review of Development Economics 6: 314328.

Cleveland, W. (1979) 'Robust locally weighted regression and smoothing scatterplots', Journal of the American Statistical Association 74: 829-836.

Cleveland, W., Devlin, S. and Grosse, E. (1988) 'Regression by local fitting', Journal of Econometrics 37: 87-114.

Crossley, T., Low, H. and Smith, S. (2011) 'Do consumers gamble to convexity?' Institute for Fiscal Studies Working Paper W11/07, London.

Dagnelie, O. and LeMay-Boucher, P. (2009) 'ROSCA participation in Benin: a commitment issue’, Instituto de Analisis Economico CSIC, Spain.

Deaton, A. (1997) The Analysis of Household Surveys: A Microeconometric Approach to Development Policy, The John Hopkins University Press: Baltimore and London.

Handa, S. and Kirton, C. (1999) 'The economics of Rotating Savings and Credit Associations: evidence from the Jamaican 'Partner', Journal of Development Economics 60: 173-194.

Heckman, J. (1981) 'Statistical models for discrete panel data', in Structural Analysis of Discrete Data with Econometric Applications, ed. C. F. Manski and D. McFadden, 114-178, Cambridge: MIT Press.

Klonner, S. (2003) 'Rotating saving and credit associations when participants are risk averse’, International Economic Review 44: 979-1005.

Lipton, M. and M. Ravallion (1994) 'Poverty and policy', In Handbook of Development Economics, Vol. 3 (ed. Jere Behrman and T.N. Srinivasan), Amsterdam: NorthHolland.

Ng, Yew-Kwang (1965) "Why do people buy lottery tickets? Choices involving risk and the indivisibility of expenditure," The Journal of Political Economy 73: 530-535.

World Bank (1996) 'Promoting intermediate means of transport', SSATP working paper 20, Sub-Saharan African Transport Policy Program, Approach paper by I.T. Transport Ltd, the World Bank and Economic Commission for Africa. 


\section{Appendix}

\section{Proof of Proposition 1.}

At any arbitrary value of $a$, say $\hat{a} \in[a, S]$, using (3)-(5), we have:

$$
\left.\frac{\partial\left[u^{\prime}(H) / u^{\prime}(L)\right]}{\partial S}\right|_{a=\hat{a}}=R\left[\frac{u^{\prime \prime}(H) u^{\prime}(L)-u^{\prime}(H) u^{\prime \prime}(L)}{\left(u^{\prime}(L)\right)^{2}}\right] ;
$$

and, analogously, at any arbitrary value of $b$, say $\hat{b} \in[0, S-\underline{a}]$,

$$
\left.\frac{\partial\left[u^{\prime}(H) / u^{\prime}(L)\right]}{\partial S}\right|_{b=\hat{b}}=\left[\frac{u^{\prime \prime}(H) u^{\prime}(L)(R+r+2 d)-u^{\prime}(H) u^{\prime \prime}(L)}{\left(u^{\prime}(L)\right)^{2}}\right] .
$$

If the coefficient of absolute risk aversion $\mathfrak{R}_{A} \equiv-\frac{u^{\prime \prime}(S)}{u^{\prime}(S)}$ is non-decreasing (resp. decreasing) in wealth, then (since $H>L$ ), $\left[u^{\prime \prime}(H) u^{\prime}(L)-u^{\prime}(H) u^{\prime \prime}(L)\right] \leq 0$ (resp. $>0$ ). It follows that:

$$
\left.\frac{\partial\left[u^{\prime}(H) / u^{\prime}(L)\right]}{\partial S}\right|_{a=\hat{a}} \leq 0 \text { (resp. }>0 \text { ) if } \Re_{A} \text { is non-decreasing (resp. decreasing) in wealth. }
$$

If the coefficient of relative risk aversion $\mathfrak{R}_{R} \equiv \mathfrak{R}_{A} S$ is increasing in wealth, then:

$$
\frac{u^{\prime \prime}(H) H}{u^{\prime}(H)}<\frac{u^{\prime \prime}(L) L}{u^{\prime}(L)} \equiv \theta<0 ;
$$

so that:

$$
u^{\prime \prime}(H)<\frac{\theta u^{\prime}(H)}{H} ; u^{\prime \prime}(L)=\frac{\theta u^{\prime}(L)}{L} .
$$

Using (12), we get:

$$
u^{\prime \prime}(H) u^{\prime}(L)(R+r+2 d)-u^{\prime}(H) u^{\prime \prime}(L)<\frac{\theta u^{\prime}(L) u^{\prime}(H)}{H L}[(R+r+2 d) L-H] .
$$

Now, (3)-(5) imply:

$$
(R+r+2 d) L-H=2 b R(r+d) \geq 0 .
$$

Since $\theta<0$, recalling (10), it follows that:

$$
\left.\frac{\partial\left[u^{\prime}(H) / u^{\prime}(L)\right]}{\partial S}\right|_{b=\hat{b}}<0 \text { if } \Re_{R} \text { is increasing in wealth. }
$$

(a) First suppose that Assumption 1 holds, and that $\mathfrak{R}_{A}$ is non-decreasing in wealth. By Assumption 1, $\left.\frac{\partial E u^{R}}{\partial a}\right|_{S=2 \underline{a}, a=\underline{a}}>0$. Since $\mathfrak{R}_{A}$ is non-decreasing in wealth, it follows from (7) and (11) that:

$$
\text { for every } S \in(\underline{a}, \underline{2} \underline{a}],\left.\frac{\partial E u^{R}}{\partial a}\right|_{a=\underline{a}}>0 \text {. }
$$


Notice now that (14) implies $\left.\frac{\partial E u^{R}}{\partial b}\right|_{S=\underline{a}, b=0}<0$; furthermore, by Assumption 1, $\left.\frac{\partial E u^{R}}{\partial s}\right|_{S=2 \underline{a}, b=0}>0$. Non-decreasing absolute risk aversion necessarily implies increasing relative risk aversion. Hence, noting (7) and (13), we get:

there exists $\tilde{S} \in(\underline{a}, 2 \underline{a})$ such that: (i) $\left.\frac{\partial E u^{R}}{\partial b}\right|_{S=\tilde{S}, b=0}=0$ and (ii) for every $S<\tilde{S}$ (resp. $>\widetilde{S}$ ), $\left.\frac{\partial E u^{R}}{\partial b}\right|_{b=0}<0$ (resp. $>0$ ).

Lastly, if at some $\tilde{S}, \hat{a},\left.\frac{\partial E u^{R}}{\partial a}\right|_{S=\tilde{S}, a=\hat{a}}=0$, then, by (7) and (11), at every $S>\tilde{S}$ (resp. $S<\tilde{S}$ $\left.\frac{\partial E u^{R}}{\partial a}\right|_{a=\hat{a}} \leq 0$ (resp. $\geq 0$ ). Recalling (8), (14) and (15), Proposition 1(a) follows.

(b) Now suppose Assumption 1 holds; additionally, $\left.\frac{\partial E u^{R}}{\partial a}\right|_{S=\underline{a}=a}>0$ and $\Re_{A}$ is decreasing in wealth but $\mathfrak{R}_{R}$ is increasing. Then again, noting (7) and (11), we get (14), and noting (7) and (13), we get (15). If at some $\tilde{S}, \hat{a},\left.\frac{\partial E u^{R}}{\partial a}\right|_{S=\tilde{S}, a=\hat{a}}=0$, then, by (7) and (11), at every $S>\tilde{S}$ (resp. $S<\tilde{S})\left.\frac{\partial E u^{R}}{\partial a}\right|_{a=\hat{a}}>0$ (resp. $\leq 0$ ). Recalling (8), (14) and (15), Proposition 1(b) follows. 
Figure 1

Propensity to save in ROSCA by household expenditure

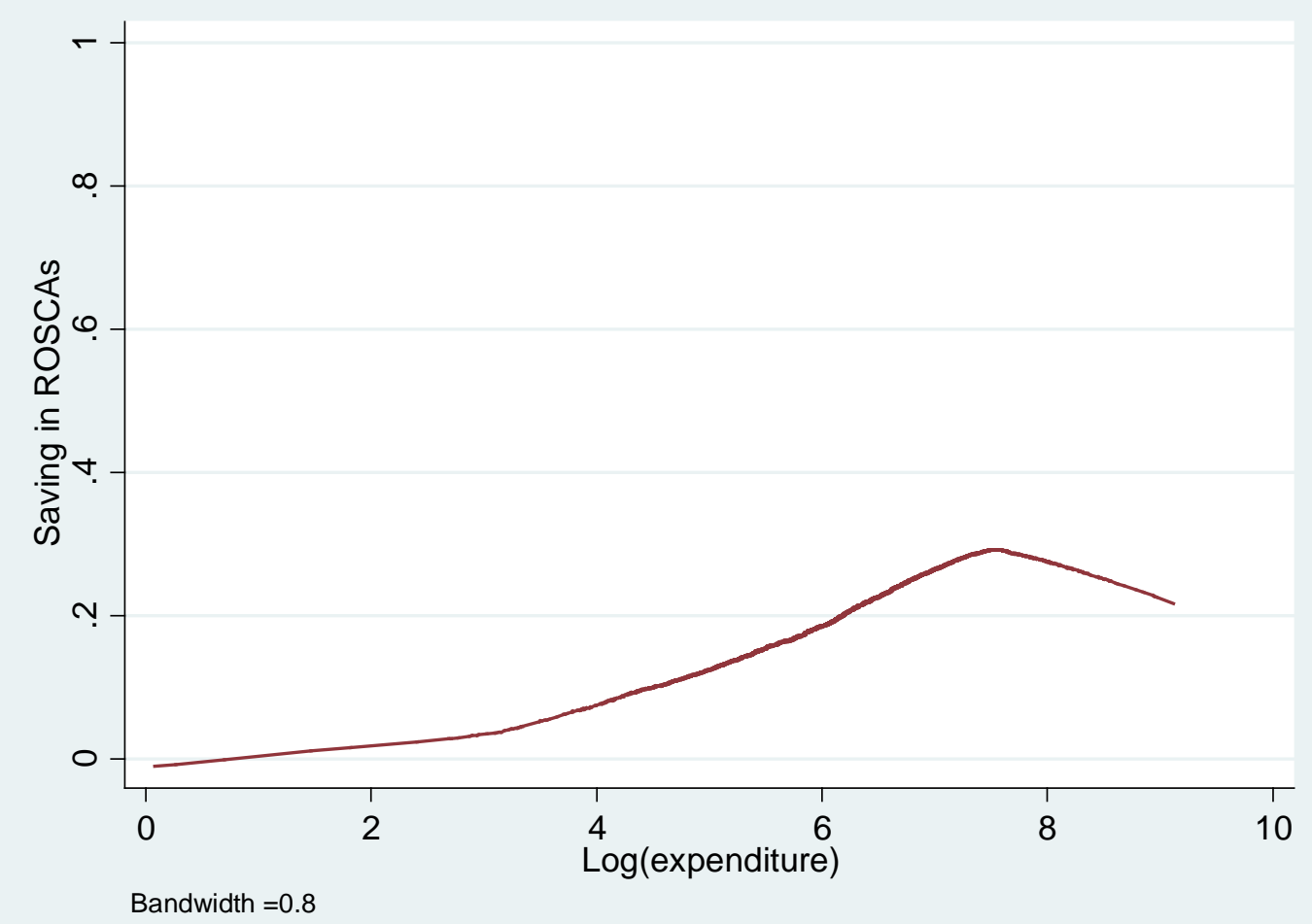

Figure 2

Propensity to save in bank by household expenditure

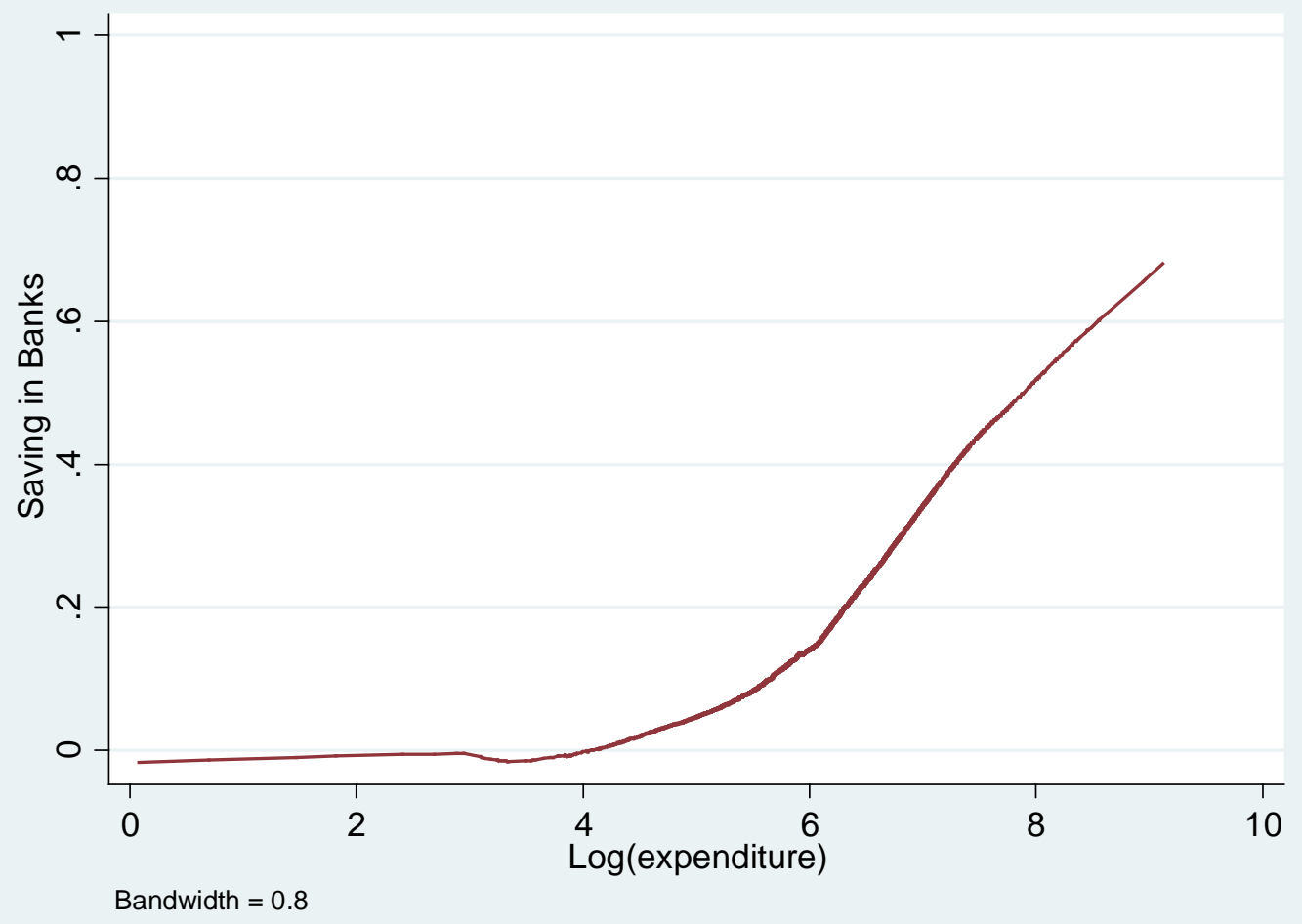


Figure 3

Propensity to save in ROSCA and bank by household expenditure

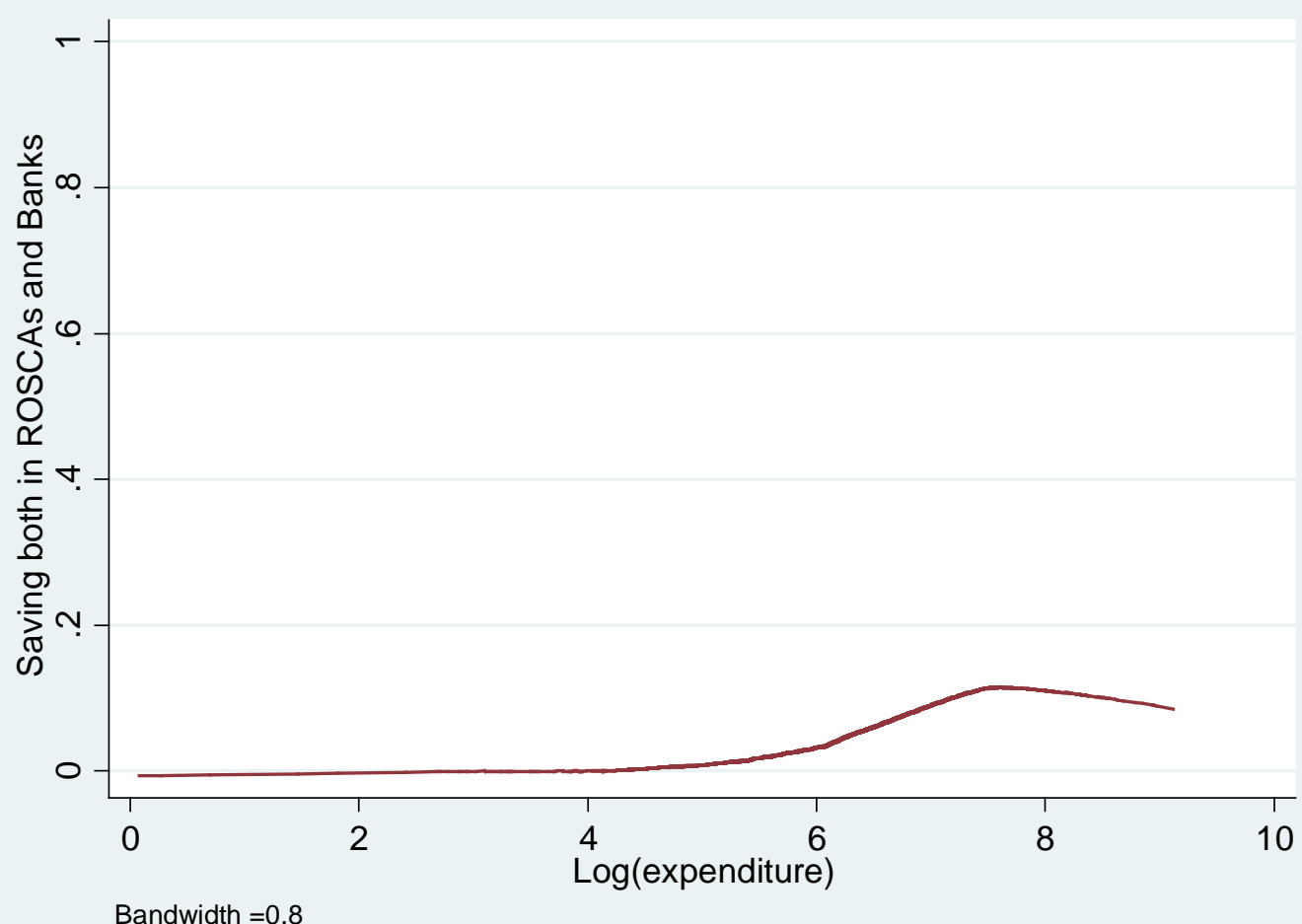

Figure 4

Amount of ROSCA saving by level of household expenditure

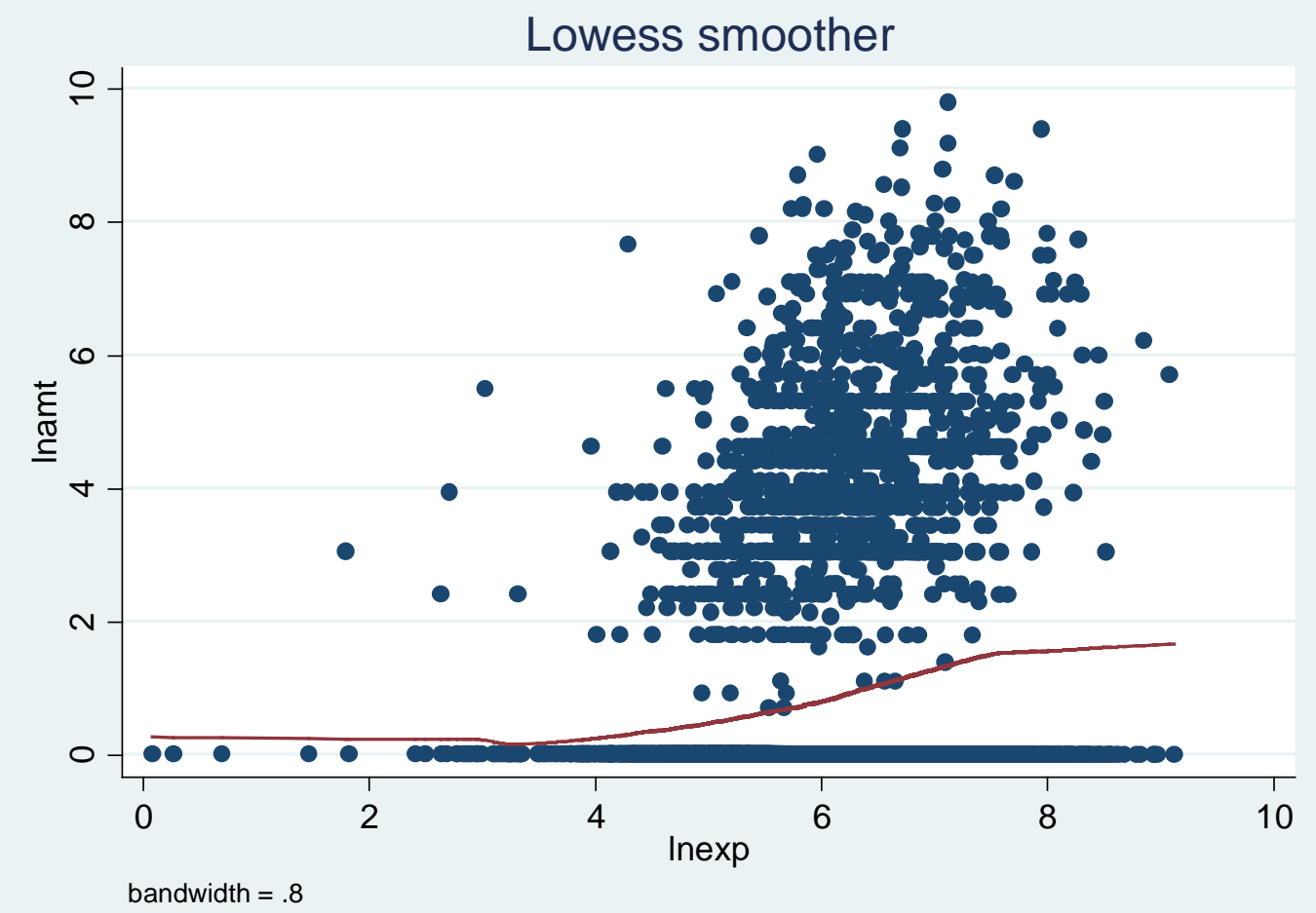

